\title{
Application of Fishery-independent Data as an Alternative Source for Determining Relative Abundance Indices of Blue Marlin, Makaira nigricans (Actinopterygii: Perciformes: Istiophoridae) in the North-eastern Indian Ocean
}

\author{
Bram Setyadji ${ }^{1, *}$ (D), Denham Parker ${ }^{2,3}$, Sheng-Ping Wang ${ }^{4}$ \\ ${ }^{1}$ Research Institute for Tuna Fisheries, Bali, Indonesia. \\ ${ }^{2}$ Forestry and Fisheries (DEFF), Department of Environment, Cape Town, South Africa. \\ ${ }^{3}$ University of Cape Town, Department of Biological Sciences, Cape Town, South Africa. \\ ${ }^{4}$ National Taiwan Ocean University, Department of Environmental Biology and Fisheries Science, National Taiwan \\ Ocean University, Keelung, Taiwan.
}

How to cite

Setyadji, B., Parker, D., Wang, S.-P. (2022). Application of Fishery-independent Data as an Alternative Source for Determining Relative Abundance Indices of Blue Marlin, Makaira nigricans (Actinopterygii: Perciformes: Istiophoridae) in the North-eastern Indian Ocean. Turkish Journal of Fisheries and Aquatic Sciences, 22(5), TRJFAS19142. http://doi.org/10.4194/TRJFAS19142

\section{Article History}

Received 05 February 2021

Accepted 17 December 2021

First Online 03 January 2022

\section{Corresponding Author}

Tel.: +62726201

E-mail: bramsetyadji@kkp.go.id

\section{Keywords}

Logbook

Scientific observer

Billfish

Catch and effort

By-catch

\begin{abstract}
The present study aimed to determine the abundance index of blue marlin, Makaira nigricans (Lacepède, 1802) utilizing fishery-independent data, i.e., scientific observer, and attempted to bridge the research's gap for low coverage information in the northeastern Indian Ocean. A total of 2,984 set-by-set observer data from 2006-2018, spatially disaggregated by one-degree blocks, were obtained from the Indonesian scientific observer program following commercial longline fleets. A delta-lognormal model was chosen to fit the dataset, using catch as the response variable with seven covariates. A backward procedure based on AIC, BIC and $\mathrm{R}^{2}$ were used to select the best model. Overall, the delta-Gamma performs better when modelling data with a high proportion of zeros than other traditional models. The blue marlin CPUE trend is relatively stable over time, despite the inter-annual fluctuations, which are likely a result of natural variation in the population as opposed to operational changes or inter-annual environmental variation. Given the low spatial coverage compared to logbook data, scientific observer data performed well and produced a robust abundance index of blue marlin in the northeastern Indian Ocean.
\end{abstract}

\section{Introduction}

Relative indices of abundance, such as catch-perunit-effort (CPUE), are generally developed from fishery-dependent data (e.g., logbook data), which is considered to be a reliable source (Carruthers et al., 2011; Fonteneau \& Richard, 2003; Maunder \& Punt, 2004). However, fleet-specific behaviour and changes thereof complicates the development of abundance indices. In such cases, expert knowledge regarding changes in fleet dynamics and how such changes may influence the logbook data received by scientists is paramount to developing indices that accurately depict true fish abundance.
In the case of Indonesian tuna and tuna-like fisheries, establishing fishery-dependent data to model the relative abundance indices is still a major challenge. Although the Ministry of Marine Affairs and Fisheries (MMAF) reiterated the obligation of logbook data collection, especially for tuna longline fleets in 2010 (Sunoko \& Huang, 2014), low compliance from fishers means this data has failed to capture the fisheries dynamics. Despite improvements having been made, such as the introduction of electronic form of logbook in early 2014 (Nugroho et al., 2017), the level of coverage remains below $10 \%$ (Geehan, 2018) and the data would not be adequate for analysis until it reaches the level of consistency for an extended time. 
Therefore, finding an alternative data source is essential, considering the importance of Indonesian tuna and tuna-like fisheries in the northeastern Indian Ocean. In 2005 a joint research initiative between Indonesia and Australia (ACIAR Project FIS/2002/074) initiated a trial of scientific observer program for the Indonesian tuna longline fishery (Proctor et al., 2011), which the Research Institute subsequently adopted for Tuna Fisheries (RITF) in 2011. The program initially intended to provide information additional to logbook data but has become the primary source information for modelling the abundance of tuna and tuna-like species, especially for marlins species (Hartaty, Setyadji, \& Fahmi, 2019; Hartaty, Setyadji, Nishida, et al., 2019; Jatmiko et al., 2019; Rochman et al., 2017; Setyadji, Andrade, et al., 2018; Setyadji \& Fahmi, 2020).

Blue marlin Makaira nigricans (Lacépède, 1802) was chosen as the specific interest as it is considered a vital non-target species from industrial and artisanal fisheries worldwide. The total reported global catch exceeded 38,000 tons in 2013, wherein the most significant proportion ( $95 \%$ ) was harvested from the Pacific and Indian oceans. Less than $5 \%$ came from the Atlantic Ocean (Chen et al., 2016). In the Indian Ocean, the catch trend has steadily increased since the 1980s, with longline fisheries accounting for most catch (70\%), followed by gillnet and troll/hand line (IOTC-WPB17, 2019). Previously, the contribution from the Indonesian fleet during the period 2013-2017 was thought to be around $30 \%(\sim 3,900$ tons) of the total catch in the Indian Ocean, ranked second after the Taiwanese fleet (IOTCWPB16, 2018). However, these catches were revised to 865 MT (9\%) to refine the methodology to estimate catch (IOTC-WPDCS14, 2018).

Blue marlin stocks are overexploited (ICCAT, 2018; IOTC-WPB17, 2019; ISC, 2016; Pons et al., 2017). The
2019 assessment of the Indian Ocean blue marlin stock strongly indicated the stock was overfished and subject to overfishing (IOTC-WPB17 2019). Assessment predictions advised a high probability $(>80 \%)$ of violating the MSY-based reference points in the following ten years if the high catch levels were maintained (IOTCWPB17, 2019). However, uncertainty in abundance indices and nominal catches, especially in the northeastern Indian Ocean where the Indonesian longline fleet traditionally operated, was identified as a concern when evaluating the stock status based on the applied assessment approaches.

The northeastern Indian Ocean is a productive fishing area concerning blue marlin catches but is often poorly represented in their assessment due to the low coverage of catch data. This study aims to address this by producing a blue marlin abundance index for the region using fishery-independent data from the Indonesian Observer Program. Such an index would undoubtedly help assess the stock of blue marlin, which is a vital fishery resource in the Indian Ocean.

\section{Materials and Methods}

At the highest spatial resolution, a total of 2,984 shot by shot catch and effort data from January 2006 to December 2018 were obtained from the Indonesian scientific observer programme, which covers commercial tuna longline vessels. The length of fishing trips ranged from three weeks to three months. The main fishing grounds cover the western and southern part of Indonesian waters, extending from $75^{\circ} \mathrm{E}$ to $35^{\circ} \mathrm{S}$ (Figure 1). The catch rate was expressed as the number of blue marlins caught per 1000 hooks. In addition, to catch and effort information, each daily record also included temporal (year and month) and spatial

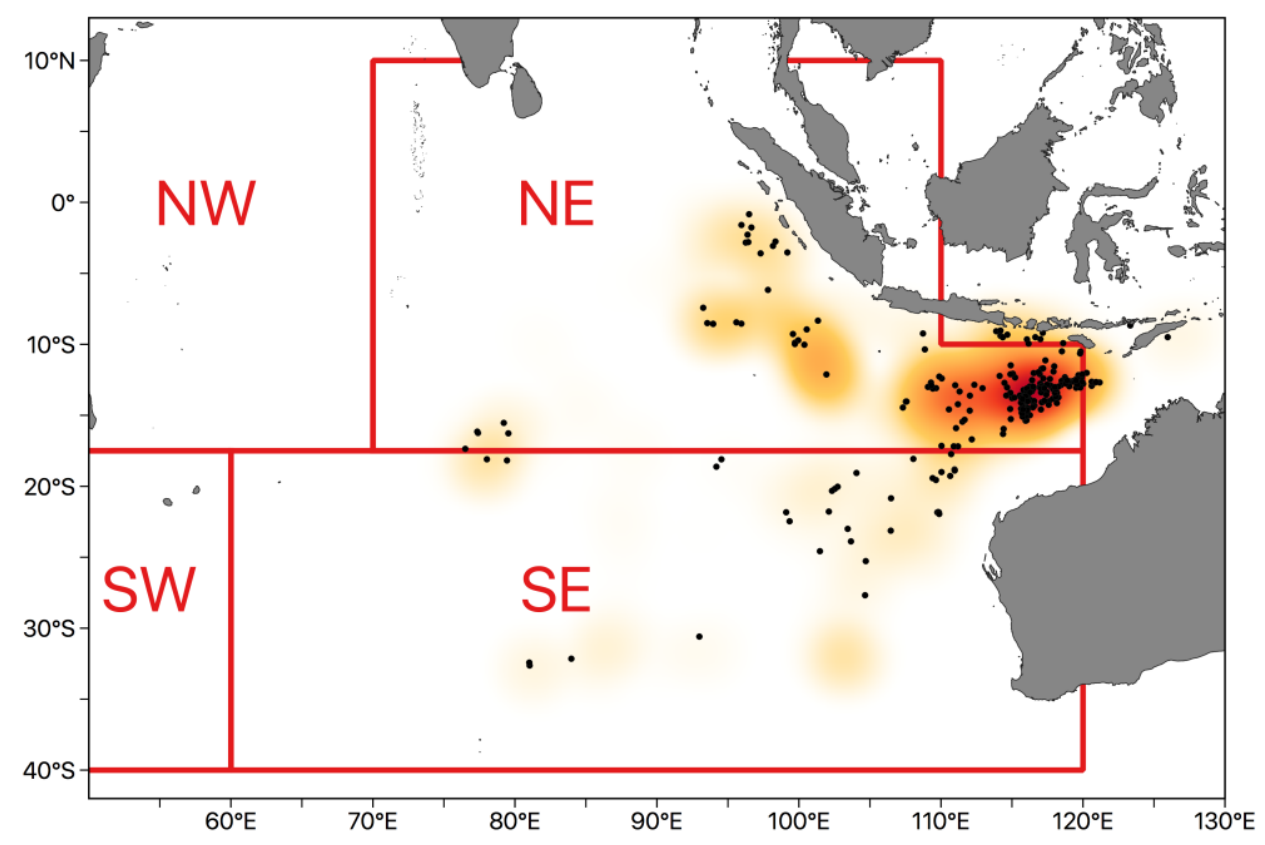

Figure 1. Map of the fishing area where the observer data were collected. After filtering the data, the northeastern (NE) area was the only area used for analysis. 
information (latitude and longitude) based on where the set is commenced. The covariates included in the analyses were selected based on their likely impact on the catch-rate of blue marlin, as recorded by previous studies (Fonteneau \& Richard, 2003; Yokoi et al., 2016; Zhou et al., 2019). These covariates are Year, Quarter, Number of Hooks Between Floats (HBF), Soak Time, Start Set, and Moon Phase. Both Year and Quarter were used as categorical (factor) explanatory variables. $H B F$ was set as continuous instead of categorical since both approaches resulted in similar results (Setyadji \& Fahmi, 2020).

On the other hand, Soak time was calculated as the time elapsed between the start of the longline setting and the beginning of hauling off the longline and rounded to the nearest integer, and also set as a continuous variable. Start Set was included in the model to account for diurnal variation in fishing. Moon Phase, introduced as a daily (where the set is commenced) index of moon fraction between 0 (new moon) and 1 (full moon), was calculated using a lunar package (Lazaridis, 2014). To account for the effect of cyclic behaviour, the Moon Phase was defined by the following function (Sadiyah et al., 2012):

$$
\begin{aligned}
& \text { Moon }=\sin (2 \pi x \text { moon phase })+ \\
& \cos (2 \pi x \text { moon phase }) \quad 1)
\end{aligned}
$$

\section{Data Filtering}

Catch data for billfishes from the Indonesian tuna longline fishery inherently has a high proportion of zerocatch-per-set occurrence (Setyadji, Andrade, et al., 2018). It was acknowledged that the predominance of zero catches could be driving the previous model outputs as the CPUE trends do not appear to be biologically plausible (IOTC-WPB16, 2018). Initially, the mean annual proportion of zero catches from the data was approximately $91 \%$. In an attempt to reduce it, three filters were applied to the data:

1. Data collected in 2005 were excluded from analysis, as it was the beginning of the trial scientific observer program and therefore it might contain species misidentification;
2. Spatial coverage of the scientific observer data, from the northeastern to the southeastern Indian Ocean, ranged from $0^{\circ}-33^{\circ} \mathrm{S}$ and $75^{\circ}-129^{\circ} \mathrm{E}$ (Figure 1). However, the temporal coverage was not completed for the data collected in the southern areas. Moreover, the positive sets for blue marlin were concentrated in the northeastern region. Therefore, the data used for analysis was limited to the area north of $17.5^{\circ} \mathrm{S}$ or northeastern area (NE) according to the IOTC statistical areas applied to swordfish (Nishida \& Wang, 2006) (Figure 1);

3. Data were subset only to include trips where one or more blue marlin was caught.

\section{Modelling Approach}

Previous studies suggested that although conventional model distributions such as Poisson, negative binomial, zero-inflated, and hurdle could be used for modelling zero-inflated catch data, caution should be applied when interpreting the model outputs (Jatmiko et al., 2017; Setyadji, Andrade, et al., 2018; Setyadji et al., 2017). Therefore, a generalized linear model (GLM) with an assumed delta-gamma distribution was applied to standardize the blue marlin CPUE from the Indonesian tuna longline fishery. Since it has been proven better to model by-catch species, i.e. marlins, catch data usually consist of a high proportion of zeros (Campbell et al., 2017; Wang, 2018).

The model was run with the following variables: Year, Quarter, HBF, Moon, Soak Time and Start Set. To avoid overfitting, no interactions among variables were included. Therefore, the gamma and delta components of the GLM were conducted as follows:

Gamma model for CPUE of positive catch:

$$
\begin{aligned}
\log (\text { CPUE })=\mu & + \text { Year }+ \text { Quarter }+H B F+\text { Moon } \\
& + \text { Soak Time }+ \text { Start Set }+\varepsilon^{\text {gamma }}
\end{aligned}
$$

Delta model for presence and absence of catch:

$$
\begin{gathered}
\mathrm{P} / \mathrm{A}=\mu+\text { Year }+ \text { Quarter }+H B F+\text { Moon }+ \text { Soak Time } \\
+ \text { Start Set }+\varepsilon^{\text {del }}
\end{gathered}
$$

\begin{tabular}{|c|c|c|}
\hline Probability model & Probability function & Hypothesis \\
\hline Negative Binomial & $P(Y=y)=\frac{\Gamma(y+1 / a)}{\Gamma(y+1) \Gamma(1 / a)} \cdot \frac{(a \mu)^{y}}{(1+a \mu)^{y+1 / a}}$ & $\begin{array}{l}\text { Nominal catches are } \\
\text { overdispersed }\end{array}$ \\
\hline $\begin{array}{l}\text { Zero-inflated Negative } \\
\text { Binomial }\end{array}$ & $P(Y=y)=\left\{\begin{array}{cl}p+(1-p) \frac{1}{(1+\alpha \mu)^{\frac{1}{\alpha}}} & y=0 \\
(1-p) \frac{\Gamma\left(y+\frac{1}{\alpha}\right)}{\Gamma(y+1) \cdot \Gamma\left(\frac{1}{\alpha}\right)} \cdot \frac{\alpha \mu^{y}}{(1+\alpha \mu)^{y+\frac{1}{\alpha}}} & y>0\end{array}\right.$ & $\begin{array}{l}\text { Nominal catches are } \\
\text { overdispersed with an excess } \\
\text { of zeros }\end{array}$ \\
\hline Tweedie & $P\left(Y: \mu, \sigma^{2}, p\right)=a\left(y: \mu, \sigma^{2}, p\right) \exp \left\{-\frac{1}{2 \sigma^{2}} d(y: \mu, p)\right\}$ & $\begin{array}{l}\text { Nominal catches are } \\
\text { overdispersed with an excess } \\
\text { of zeros }\end{array}$ \\
\hline Delta-Gamma & $\begin{array}{l}P(Y=0)=1-p \\
P(Y=y \mid y>0)=p \times\left(\frac{\lambda^{\alpha} y^{\alpha-1} \times \exp (-\lambda y)}{\Gamma(\alpha)}\right)\end{array}$ & $\begin{array}{l}\text { Nominal catches are either } \\
\text { overdispersed or under } \\
\text { dispersed }\end{array}$ \\
\hline
\end{tabular}

Table 1. Probability models and hypotheses about the capture probability of catch $(P)$ for CPUE standardization, including the probability mass or density function for the catch, and the hypothesis about nominal catches, for the negative binomial, zeroinflated negative binomial, Tweedie and delta-Gamma distributions (Rose et al., 2006; Saffari et al., 2012; Walsh \& Brodziak, 2014). 
We applied a stepwise approach for model selection, starting with a null model and incorporating variables one at a time and only selecting the variable that produced the lowest model residual deviance. This approach was repeated until model residual deviance did not decrease as new variables were added. Finally, explanatory variables were selected through a backward procedure based on Akaike Information Criterion (AIC) (Akaike, 1974), Bayesian Information Criterion (BIC) (Schwarz, 1978) and the values of the coefficient of determination $\left(R^{2}\right)$. Results from models with alternative error distributions, such as Tweedie, zeroinflated negative binomial, and simple negative binomial were also considered in this study for comparative purposes (Table 1).

The area-specific standardized CPUE trends were estimated based on the exponent of the year's adjusted means (least-square means) effects (Butterworth, 1996; Maunder \& Punt, 2004). The standardized relative abundance index was calculated by the product of the standardized CPUE of positive catches and the standardized probability of positive catches:

$$
\text { index }=e^{\log (C P U E)}\left(\frac{e^{\tilde{P}}}{1+e^{\tilde{P}}}\right)
$$

Where CPUE is the adjusting means (least-square means) of the year effect of the gamma model and $\tilde{P}$ is the adjusted means (least-square means) of the year effect of the delta model.

Maps were produced using QGIS version 3.11 (QGIS Developer Team, 2020) and the statistical analyses were carried out using $R$ software version 3.6.0 (R Core Team, 2018).

\section{Results}

Before data filtering, the initial combined dataset contained 112 trips, 2,984 sets, and almost 4 million hooks deployed. Post filtering procedures, the number of trips approximately halved. The mean observed sets deployed was 101.1 (45.8) per year or 21.4 (6.8) per trip. The total number of hooks observed was 1.6 million, with approximately 1200 hooks deployed every set using a configuration of 11 or more hooks between floats (Table 2). As a result of applying data filtering, the proportion of zero-catch-per-set decreased by $6 \%$.

In general, the nominal catches of blue marlin from the tropical areas have been relatively stable since 2006, except in 2012 when catches were notably high $(0.44$ (0.09)) fish per 1000 hooks) (Figure 2). The positive

Table 2. Summary of the annual observed fishing effort from the Indonesian tuna longline fishery for 2006-2018 (post-filtering). Values represented in means and standard error showed in parenthesis.

\begin{tabular}{|c|c|c|c|c|c|c|c|}
\hline Year & Trips & Sets & Total Hooks & \multicolumn{2}{|c|}{ Hooks per Set } & \multicolumn{2}{|c|}{ Hooks per Float } \\
\hline 2006 & 8 & 153 & 220,432 & $1,391.6$ & $(21.18)$ & 11.8 & $(0.06)$ \\
\hline 2007 & 3 & 41 & 66,577 & $1,522.5$ & (35.29) & 16.1 & $(0.04)$ \\
\hline 2008 & 8 & 155 & 182,583 & $1,389.6$ & $(23.12)$ & 11.6 & $(0.03)$ \\
\hline 2009 & 5 & 154 & 181,911 & $1,199.2$ & $(10.22)$ & 11.4 & $(0.00)$ \\
\hline 2010 & 6 & 119 & 151,787 & $1,242.0$ & (20.39) & 12.7 & $(0.11)$ \\
\hline 2011 & 3 & 105 & 110,384 & $1,046.2$ & (18.03) & 12.0 & $(0.00)$ \\
\hline 2012 & 4 & 69 & 76,008 & $1,263.2$ & $(25.38)$ & 12.8 & $(0.00)$ \\
\hline 2013 & 6 & 163 & 176,456 & $1,112.7$ & (13.36) & 12.1 & (0.08) \\
\hline 2014 & 5 & 65 & 74,779 & $1,222.6$ & (11.38) & 14.2 & $(0.01)$ \\
\hline 2015 & 2 & 32 & 40,261 & $1,161.1$ & (15.25) & 12.9 & $(0.25)$ \\
\hline 2016 & 3 & 88 & 109,064 & $1,222.1$ & (10.87) & 12.7 & $(0.09)$ \\
\hline 2017 & 4 & 60 & 65,348 & 996.4 & (15.66) & 13.8 & $(0.03)$ \\
\hline 2018 & 5 & 110 & 144,764 & $1,308.2$ & (15.93) & 14.8 & $(0.13)$ \\
\hline
\end{tabular}

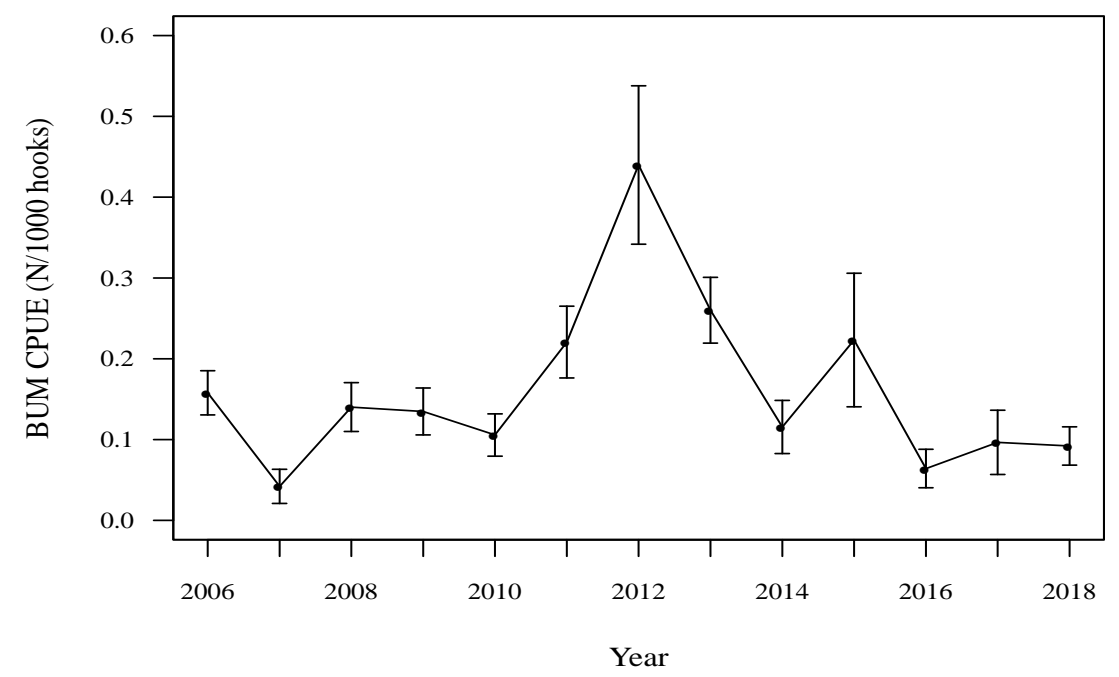

Figure 2. Nominal CPUE series (N/1000 hooks) for blue marlin caught in the Indonesian tuna longline fleet from 2006 to 2018. Vertical bars refer to the standard errors. 
anomaly in that particular year is thought to result from data filtering procedures, which caused deletion on some trips without blue marlin catch. Hence the remaining data consist of fortunately high catch at relatively low effort, which caused the spike instead of changes in true abundance. The lowest CPUE recorded was in 2007 (0.042 (0.02)) with average 0.16 (0.04) per year. The proportion of zero catch sets varied annually between $71.01 \%$ in 2012 and $93.70 \%$ in 2016, with an average value of $85.24 \%$ (Figure 3 ).

All retained effects were statistically significant, except for Moon Phase. Soak Time was excluded from both models as it had negligible influence. The deviance tables for selected Gamma models are shown in Table 3. The results indicated that Year was the most influential variable when modelling the positive catch of blue marlin, followed by targeting (HBF), season (Quarter) (Table 3). Moon Phase and Start Set were shown to have little effect on positive catches. As for the delta model, the results were quite similar, with year again proving to be the most crucial factor (Table 4). However, unlike the gamma model, the start set had considerable influence contributing to the probability of successful capture.

A comparison of standardized CPUE trends for the period 2006 - 2018, as calculated using delta-gamma (DELTA), negative binomial (NB), zero-inflated negative binomial (ZINB) and Tweedie (TWEEDIE) models, produced relatively similar outputs (Figure 4). In general, the trend is stable from 2006-2010, increases drastically after that and peaks in 2012, after which it decreases again. The DELTA model produced a smoother trend with better model performance and was chosen as it is likely to better account for the high proportion of zero catches in the data (Figure 5 and Table 5).

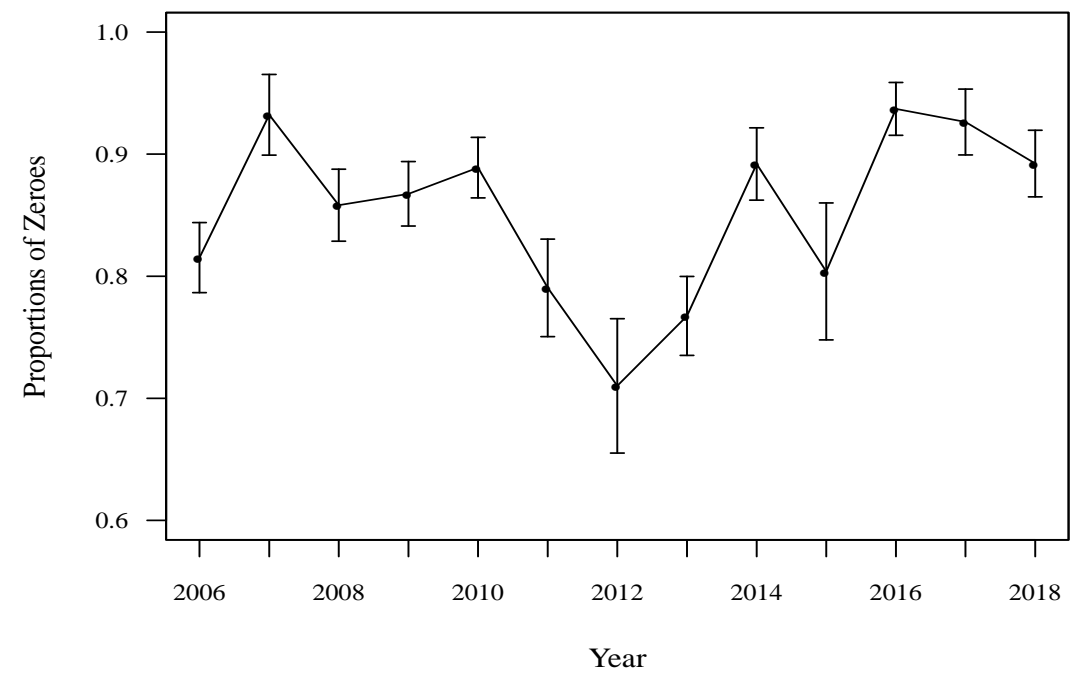

Figure 3. The proportion of zero blue marlin catches observed from the Indonesian tuna longline fleet for 2006 - 2018. Vertical bars refer to the standard errors.

Table 3. Deviance table documenting the relative importance of the explanatory variables included in the gamma model

\begin{tabular}{|c|c|c|c|c|c|c|c|}
\hline Variable & $\mathrm{Df}$ & Deviance Resid. & Df. Resid. & Deviance & $\mathrm{F}$ & $\operatorname{Pr}(>\mathrm{F})$ & \\
\hline NULL & & & 230 & 39.376 & & & \\
\hline Year & 12 & 6.790 & 218 & 32.586 & 3.4886 & 0.0001018 & $* * *$ \\
\hline Quarter & 3 & 1.709 & 215 & 30.877 & 3.5125 & 0.0161207 & $*$ \\
\hline$H B F$ & 1 & 1.224 & 214 & 29.653 & 7.5447 & 0.0065364 & $* *$ \\
\hline Moon & 1 & 0.467 & 213 & 29.186 & 2.8812 & 0.0910855 & . \\
\hline Start_Set & 1 & 0.606 & 212 & 28.580 & 3.7389 & 0.0544919 & . \\
\hline
\end{tabular}

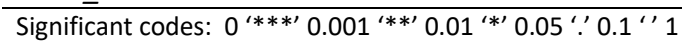

Table 4. Deviance table documenting the relative importance of the explanatory variables included in the delta model

\begin{tabular}{lcccccc}
\hline Variable & Df & Deviance Resid. & Df. Resid. & Deviance & $\operatorname{Pr}(>\mathrm{F})$ & \\
\hline NULL & & & 1571 & 1312.2 & & 0.00006 \\
Year & 12 & 46.328 & 1559 & 1265.9 & 0.03245 & $*$ \\
Quarter & 3 & 8.774 & 1556 & 1257.1 & 0.01857 & $*$ \\
HBF & 1 & 5.542 & 1555 & 1251.6 & 0.13388 & \\
Moon & 1 & 2.247 & 1554 & 1249.3 & $0.03960 *$ \\
Start_Set & 1 & 4.235 & 1553 & 1245.1 & & \\
\hline
\end{tabular}

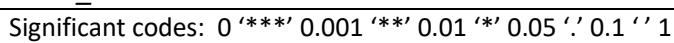




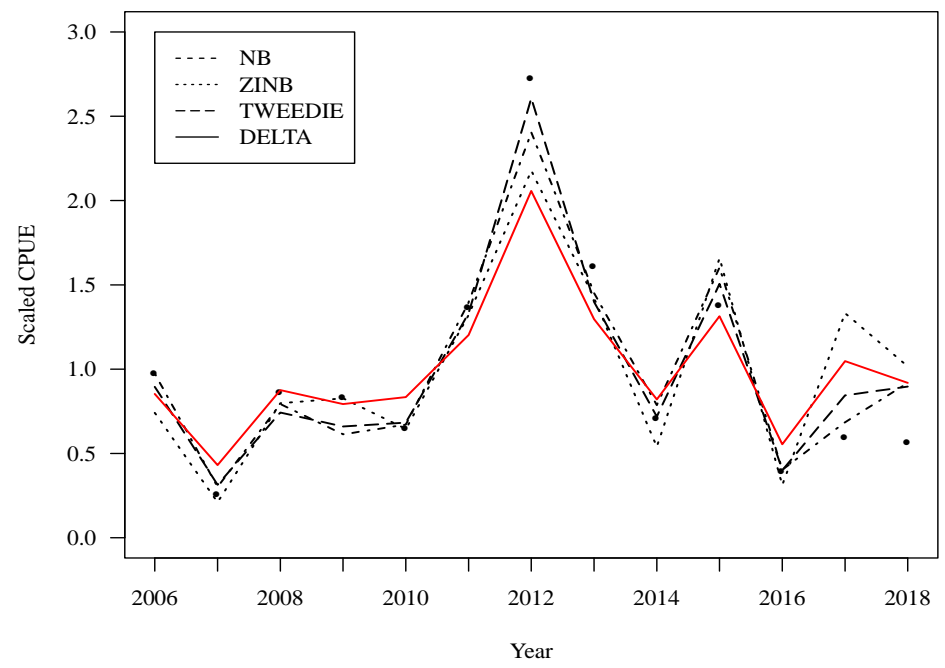

Figure 4. Standardized catch per unit effort (CPUE) of blue marlin caught in the Indonesian tuna longline fleet for 2006-2018, calculated using various models. The values were normalized by dividing by their means for comparison purposes.

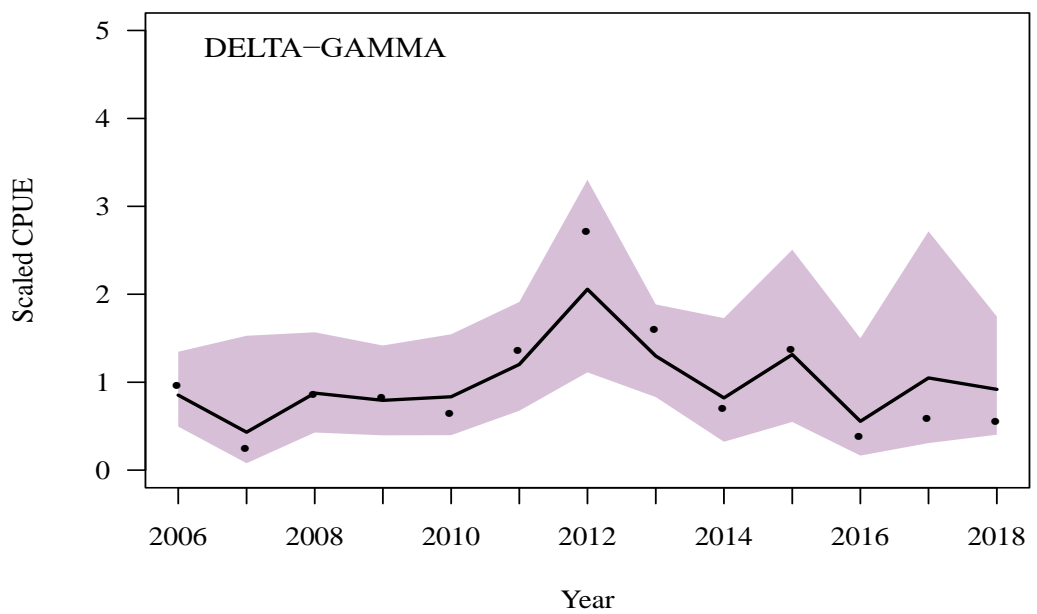

Figure 5. Final standardized catch per unit effort (CPUE) of blue marlin caught in the Indonesian tuna longline fleet for 2006 2018 , calculated using a delta-gamma model with $95 \%$ confidence interval (greyed area). The values were normalized by dividing by their means for comparison purposes.

Table 5. Summary of indicators as calculated using four model structures: Tweedie (TWEEDIE), Negative Binomial (NB), Zero-inflated with Negative Binomial (ZINB), Delta-lognormal (DELTA). The terms in the column at left indicate Akaike (AIC), Bayesian Information Criteria (BIC), and $\mathrm{R}^{2}$

\begin{tabular}{lccccc}
\hline \multirow{2}{*}{ Indicators } & \multirow{2}{*}{ TW } & \multirow{2}{*}{ NB } & \multirow{2}{*}{ ZINB } & \multicolumn{2}{c}{ DELTA } \\
\cline { 5 - 6 } & & & 1529.42 & & Gamma \\
$\mathrm{BIC}$ & 1962.38 & 1513.51 & 1722.38 & 200.73 & 1283.10 \\
$\mathrm{R}^{2}$ & 1922.38 & 1620.71 & 0.01 & 0.21 & 1384.95 \\
\hline
\end{tabular}

\section{Discussion}

Fisheries dependent data (e.g., logbook) is preferred information for deriving relative abundance indices for tuna and tuna-like fisheries. However, in Indonesia, constraints have limited the transmission of catch information from vessels to authorities. Low educational background and heavy reluctance from the skippers on sharing fisheries information has led to low acceptance of obligatory logbook submission in longline vessels (Geehan, 2018). Concern regarding data sharing (i.e., fishing ground) was likely the primary source behind the refusal. Moreover, the skipper knowledge about common names or standard codes of fishes remains questionable, especially for by-catch species, leading to misidentification on some species with similar physiology (e.g., marlins).

On the other hand, scientific observer data provides more detailed information and a high level of confidence in the data since it is obtained from welltrained personal. However, it is inherently expensive, and invariably the quantity or coverage of data is much less than what is expected from logbook data, but the quality is generally much better. Therefore, It has been 
extensively used to decrypt the catch and effort data from longline fisheries (Block et al., 2005; Huang \& Liu, 2010; Teo \& Block, 2010), especially for by-catch species which are usually not fully covered by logbook data. According to the IOTC, the minimum mandatory observer coverage for longline fleets is $5 \%$ of the total fishing effort (i.e., the total number of hooks) and does not require stratification by area, vessel or season. Therefore, each country's responsibility is to ensure that the data collected from national observer programs are sufficiently stratified to provide meaningful information. In this case, due to a strict budgeting policy, the level of Indonesian scientific observer coverage was less than $2 \%$ every year (Fahmi et al., 2020).

This study shows that, apart from the spatial limitation, the model performed well in characterizing the relative abundance of blue marlin. There was no apparent trend in catch rates, suggesting that the northeastern Indian Ocean blue marlin population has remained relatively stable for the period 2006-2018. However, this is a relatively short time series and the observed stability in the CPUE trend does not indicate a healthy population. More extended CPUE time series, such as those derived from the Japanese and Taiwanese longline fleets operating in the Indian Ocean, show an extended period of decline from 1979 until 2010 and then stabilizes (Taki et al., 2019; Wang, 2019). The most recent assessment of blue marlin in the Indian Ocean indicates that the stock is overfished and subject to overfishing. The catches of blue marlin would have to be reduced by approximately 35\% (approx. 7,800 tons) to ensure sustainability (Parker et al., 2019). As mentioned earlier, the Indonesian CPUE information from this study was included in the stock and corroborated the recent stability observed in the Japanese and Taiwanese CPUE indices.

Further, the variation in abundance of blue marlin could also be driven by some oceanographic and sociocultural phenomenon. A couple of studies found that the conditions of primary productivity strongly influence fish habitat in the southern part of Indonesian waters. Where it's strongly influenced by the sea-air interaction, significantly influenced by monsoon (Utamy et al., 2015), and the interannual ENSO and IOD (Ningsih et al., 2013; Susanto \& Marra, 2005). For example, during 2006-2018, there were several coupling events between ENSO and IOD. Some of those events correlated with semi-permanent upwelling (June - October), which might influence the catch rate of billfish. However, such an assumption wasn't incorporated in this study. Hence an in-depth investigation is required for future research. In addition, the low catch rate of tuna and billfish in the southern waters of Java might be related to inadequate primary productivity Yu et al. (2015). Also, socio-cultural influence wherein particular month of the year, during the religious events the fishing activities were usually put on hold (Setyadji, Pranowo, et al., 2018).

The two-stage delta-GLM approach has been frequently used for modelling the relative abundance of billfish species from longline fisheries (Walsh \& Brodziak, 2014; Wang, 2019). It is recommended in cases where excessive zero catch occurrences are observed (Campbell et al., 2017). The first stage of the model incorporates the pattern of the event of positive catches, while the second phase models the mean size of the positive catch rates. Zero-inflated models are also expressed in two parts. Although conceptually may be more appropriate for modelling catch data of infrequently encountered species (Minami et al., 2007), the delta-Gamma model was considered more appropriate in this study than the zero-inflated and other traditional model structure (e.g., Tweedie, negative binomial). Apart from its ability to account for the high proportion of zero catches, the delta-Gamma was also better in handling the high nominal CPUE in 2012 and gave stability to the overall series without signs of overfitting, as shown in Walsh and Brodziak (2015). However, a higher level of uncertainty progressed towards the end of the data series, which remains a lingering issue. It is likely to result from low coverage of the dataset instead of the inconsistent catches. Low data coverage is a typical restraint for scientific observer data. It would take a substantial cost (approx. $\$ 1,000,000 /$ year) to comply with the minimum requirement (i.e., $5 \%$ coverage) from regional fisheries regulation. Improving the submission and quality of logbook data should be the main priority for Indonesian authorities while maintaining the continuity of the scientific observer program. Improving deployment stratification by common fishing ground, fleet and time of the year (e.g., quarterly) would result in a more representative dataset being obtained.

\section{Conclusions}

Overall, the Delta-gamma performs better when modelling data with a high proportion of zeros than other traditional models. The blue marlin CPUE trend is relatively stable over time, despite the inter-annual fluctuations, which are likely a result of natural variation in the population as opposed to operational changes or inter-annual environmental variation. The final model still possesses a high level of uncertainty and, therefore, can be further improved. Future research should focus on incorporating large-scale ecological data or habitat suitability information.

\section{Ethical Statement}

Not applicable.

\section{Funding Information}

This work was supported through project FIS/2002/074 of the Australian Centre for International Agricultural Research between 2005-2010 and continued by the state budget of the Indonesian Government 2011-2018. 


\section{Author Contribution}

B.S. and D.P. was contributed in sharing ideas, designed/re-designed and performed the initial statistical models, and draft the base paper. D.P. and SP.W. were contributed in providing critical revision on the article, cross-checked the final statistical models, proofreading and providing final approval of the version to publish.

\section{Conflict of Interest} interest.

The authors declare that they have no conflict of

\section{Acknowledgements}

The authors would like to thank all scientific observers of the Research Institute for Tuna Fisheries (RITF) and national observers of Directorate General of Capture Fisheries (DGCF) for their contribution in collecting data throughout the years. We also would like to extend our gratitude to various organizations, namely, Commonwealth Scientific and Industrial Research Organization (CSIRO), the Australian Centre for International Agricultural Research (ACIAR) and the Research Institute for Capture Fisheries (RCCF).

\section{References}

Akaike, H. (1974). A new look at the statistical model identification. IEEE Transactions on Automatic Control, 19(6), 716-723. https://doi.org/10.1109/TAC.1974.1100705

Block, B.A., Teo, S.L., Walli, A., Boustany, A., Stokesbury, M.J., Farwell, C.J., Weng, K.C., Dewar, H., \& Williams, T.D. (2005). Electronic tagging and population structure of Atlantic bluefin tuna. Nature, 434(7037), 1121-1127.

Butterworth, D.S. (1996). A possible alternative approach for generalised linear model analysis of tuna CPUE data. Collective Volume of Scientific Papers, 45, 123-124.

Campbell, R.A., Zhou, S., Hoyle, S., Hillary, R., Haddon, M., \& Auld, S. (2017). Developing innovative approaches to improve CPUE standardisation for Australia's multispecies pelagic longline fisheries (Final Report FRDC Project No. 2014-021). Fisheries Research Development Corporation.

Carruthers, T.R., Ahrens, R.N., McAllister, M.K., \& Walters, C.J. (2011). Integrating imputation and standardization of catch rate data in the calculation of relative abundance indices. Fisheries Research, 109(1), 157-167.

Chen, H., Chang, C.-H., Sun, C.-L., Shao, K.-T., Yeh, S.-Z., \& DiNardo, G. (2016). Population structure of blue marlin, Makaira nigricans, in the Pacific and Eastern Indian Oceans. Zoological Studies, 55(33). https://doi.org/10.6620/ZS.2016.55-33

Fahmi, Z., Setyadji, B., Mardi, S., Sulistyaningsih, R.K., \& Hartaty, H. (2020). Indonesia southern bluefin tuna fisheries a national report 2019. Paper Presented at the Twenty Fifth Meeting of the Extended Scientific Committee 31 August-7 September 2020, CCSBTESC/2008/SBT Fisheries - Indonesia, 13 pp.
Fonteneau, A., \& Richard, N. (2003). Relationship between catch, effort, CPUE and local abundance for non-target species, such as billfishes, caught by Indian Ocean longline fisheries. Marine and Freshwater Research, 54(4), 383-392.

Geehan, J. (2018). Revision to the IOTC scientific estimates of Indonesia's fresh longline catches. Paper Presented at 14th Working Party on Data Collection and Statistics, Mahe, Seychelles, 29 November-1 December 2018. IOTC2018-WPDCS14-23, 14.

Hartaty, H., Setyadji, B., \& Fahmi, Z. (2019). Updated information on catch and effort of yellowfin tuna (Thunnus albacares) from Indonesian tuna longline fishery. Paper Presented at 21st Working Party on Tropical Tuna, San Sebastian, Spain, 21-26 October 2019. IOTC-2019-WPTT21-42, 6.

Hartaty, H., Setyadji, B., Nishida, T., \& Fahmi, Z. (2019). CPUE Standardization of Bigeye Tuna, Thunnus obesus (Lowe, 1839) from Indonesian Tuna Longline Fishery in the Eastern Indian Ocean. Paper Presented at 21st Working Party on Tropical Tuna, San Sebastian, Spain, 21-26 October 2019. IOTC-2019-WPTT21-31, 11.

Huang, H.-W., \& Liu, K.-M. (2010). Bycatch and discards by Taiwanese large-scale tuna longline fleets in the Indian Ocean. Fisheries Research, 106(3), 261-270. https://doi.org/10.1016/j.fishres.2010.08.005

ICCAT. (2018). Report of the 2018 ICCAT blue marlin stock assessment meeting (p. 45). The International Commission for the Conservation of Atlantic Tunas (ICCAT).

IOTC-WPB16. (2018). Report of the 16th Session of the IOTC Working Party on Billfish (Working Party Report IOTC2018-WPB16-R[E]; p. 97). Indian Ocean tuna Commission (IOTC).

http://iotc.org/sites/default/files/documents/2018/11/ IOTC-2018-WPB16-RE_FINAL_-_DO_NOT_MODIFY.pdf

IOTC-WPB17. (2019). Report of the 17th Session of the IOTC Working Party on Billfish (Working Party Report IOTC2019-WPB17-R[E]; p. 92). Indian Ocean Tuna Commission (IOTC).

https://iotc.org/sites/default/files/documents/2019/10 /IOTC-2019-WPB17-RE_-_FINAL.pdf

IOTC-WPDCS14. (2018). Report of the 14th Session of the IOTC Working Party on Data Collection and Statistics. (Working Party Report IOTC-2018-WPDCS14-R[E]; p. 71). Indian Ocean tuna Commission (IOTC). https://iotc.org/sites/default/files/documents/2019/05 /IOTC-2018-WPDCS14-RE_FINAL.pdf

ISC. (2016). Stock Assessment Update for Blue Marlin (Makaira nigricans) in the Pacific Ocean through 2014 (p. 92) [Report of the billfish working group]. International Scientific Committee for Tuna and Tuna-Like Species in the North Pacific Ocean.

Jatmiko, I., Andrade, H., \& Nugraha, B. (2017). Delta model approach for CPUE standardization of swordfish (Xiphias gladius Linnaeus, 1978) caught by Indonesian longline fleet in the Eastern Indian Ocean. Indonesian Fisheries Research Journal, 23(1), 7-15. https://doi.org/10.15578/ifrj.23.1.2017.7-15

Jatmiko, I., Setyadji, B., \& Fahmi, Z. (2019). Standardized CPUE of blue shark (Prionace glauca) caught by Indonesian longline fleet in the eastern Indian Ocean. Paper Presented at 15th Working Party on Ecosystem and ByCatch, La Reunion, France, 3-7 September 2019. IOTC2019-WPEB15-18, 13. 
Lazaridis, E. (2014). lunar: Lunar Phase \& Distance, Seasons and Other Environmental Factors. http://statistics.lazaridis.eu

Maunder, M.N., \& Punt, A.E. (2004). Standardizing catch and effort data: A review of recent approaches. Fisheries Research, 70, 141-159. https://doi.org/10.1016/j.fishres.2004.08.002

Minami, M., Lennert-Cody, C.E., Gao, W., \& Román-Verdesoto, M. (2007). Modeling shark bycatch: The zero-inflated negative binomial regression model with smoothing. Fisheries Research, 84(2), 210-221. https://doi.org/10.1016/j.fishres.2006.10.019

Ningsih, N.S., Rakhmaputeri, N., \& Harto, A.B. (2013). Upwelling variability along the southern coast of Bali and in Nusa Tenggara waters. Ocean Science Journal, 48(1), 49-57. https://doi.org/10.1007/s12601-013-0004-3

Nishida, T., \& Wang, S.-P. (2006). Standardization of swordfish (Xiphias gladius) CPUE of the Japanese tuna longline fisheries in the Indian Ocean. Paper Presented at OTC 5 th WPB Meeting, March 27-31, 2006, Colombo, Sri Lanka, 10.

Nugroho, H., Sufyan, A., \& Wiadnyana, N.N. (2017). Aplikasi teknologi elektronik log book penangkapan ikan untuk mendukung pengelolaan perikanan. Jurnal Kelautan Nasional, 10(3), 113-124.

Parker, D., Winker, H., \& Kerwath, S.E. (2019). Continuity runs of the Andrade (2016) Bayesian state space surplus production model assessment of Indian ocean blue marlin (Makaira nigricans) stock using JABBA. Paper Presented at 17th Working Party on Billfish, La Reunion, France, 9-12 September 2019. IOTC-2019-WPB17-20a, $15 \mathrm{pp}$.

Pons, M., Branch, T.A., Melnychuk, M.C., Jensen, O.P., Brodziak, J., Fromentin, J.M., Harley, S.J., Haynie, A.C., Kell, L.T., Maunder, M.N., Parma, A.M., Restrepo, V.R., Sharma, R., Ahrens, R., \& Hilborn, R. (2017). Effects of biological, economic and management factors on tuna and billfish stock status. Fish and Fisheries, 18(1), 1-21. https://doi.org/10.1111/faf.12163

Proctor, C., Purwanto, Budiman, A., Nurhakim, S., Prisantoso, B.I., Andamari, R., Sadiyah, L., Dowling, N., Davies, C.R., Davis, T.L., Wudianto, Nikijuluw, V., Poernomo, A., Tambunan, P., Perbowo, N., Retnowati, D., Merta, I.G.S., Nugraha, B., Triharyuni, S., ... Team enumerators. (2011). Project Summary - ACIAR Project FIS/2002/074 Capacity to monitor, analyse and report on Indonesian tuna fisheries. Australian Centre for International Agricultural Research, Canberra.

QGIS Developer Team. (2020). QGIS Geographic Information System. Open Source Geospatial Foundation Project. http://qgis.osgeo.org/

R Core Team. (2018). R: A Language and Environment for Statistical Computing. R Foundation for Statistical Computing. https://www.R-project.org/

Rochman, F., Setyadji, B., \& Wujdi, A. (2017). Standardizing CPUE of albacore tuna (Thunnus alalunga Bonnaterre, 1788) on tuna longline fishery in Eastern Indian Ocean. Indonesian Fisheries Research Journal, 23(1), 29-38. http://dx.doi.org/10.15578/ifrj.23.1.2017.29-38

Rose, C.E., Martin, S.W., Wannemuehler, K.A., \& Plikaytis, B.D. (2006). On the use of zero-inflated and hurdle models for modeling vaccine adverse event count data. Journal of Biopharmaceutical Statistics, 16(4), 463-481.

Sadiyah, L., Dowling, N., \& Prisantoso, B.I. (2012). Developing recommendations for undertaking CPUE standardisation using observer program data. Indonesian Fisheries Research Journal, 18(1), 19-33.

https://doi.org/10.15578/ifrj.18.1.2012.19-33

Saffari, S.E., Adnan, R., \& Greene, W. (2012). Hurdle negative binomial regression model with right censored count data. SORT: Statistics and Operations Research Transactions, 36(2), 0181-0194.

Schwarz, G. (1978). Estimating the dimension of a model. The Annals of Statistics, 6(2), 461-464.

Setyadji, B., Andrade, H.A., \& Proctor, C.H. (2018). Standardization of catch per unit effort with high proportion of zero catches: An application to black marlin Istiompax indica (Cuvier, 1832) caught by the Indonesian tuna longline fleet in the eastern Indian Ocean. Turkish Journal of Fisheries and Aquatic Sciences, 19(2), 119-129. https://doi.org/10.4194/1303-2712v19_2_04

Setyadji, B., \& Fahmi, Z. (2020). A standardized abundance index from fishery independent data: A case study of swordfish (Xiphias gladius) from Indonesian tuna longline fishery. E3S Web Conf., 147, 02016. https://doi.org/10.1051/e3sconf/202014702016

Setyadji, B., Fahmi, Z., \& Andrade, H. (2017). Standardized CPUE indices for swordfish (Xiphias gladius) from the Indonesian tuna longline fishery. Paper Presented at 15th Working Party on Billfish, San Sebastián, Spain, 1014 September 2017. IOTC-2017-WPB15-15, 14 pp.

Setyadji, B., Pranowo, W.S., \& Amri, K. (2018). Sea-air impacts on fishing season of hand line skipjack tuna Katsuwonus pelamis (Linnaeus, 1758) in Pacitan coastal waters of the south eastern Indian Ocean. Omni-Akuatika, 14(1), 1-10. http://dx.doi.org/10.20884/1.oa.2018.14.1.207

Sunoko, R., \& Huang, H.-W. (2014). Indonesia tuna fisheries development and future strategy. Marine Policy, 43, 174-183. https://doi.org/10.1016/j.marpol.2013.05.011

Susanto, R., \& Marra, J. (2005). Chlorophyll a variability. Oceanography, 18(4), 124. https://doi.org/10.5670/oceanog.2005.13.

Taki, K., ljima, H., Semba, Y., \& Nishida, T. (2019). Standardized CPUE of blue marlin (Makaira mazara) caught by Japanese longline fishery in the Indian Ocean: Analysis between 1994 and 2018. Paper Presented at 17th Working Party on Billfish, La Reunion, France, 9-12 September 2019. IOTC-2019-WPB17-19, 16 pp.

Teo, S.L., \& Block, B.A. (2010). Comparative influence of ocean conditions on yellowfin and Atlantic bluefin tuna catch from longlines in the Gulf of Mexico. PLoS One, 5(5), e10756.

Utamy, R.M., Purba, N.P., Pranowo, W.S., \& Suherman, H. (2015). The Pattern of South Equatorial Current and Primary Productivity in South Java Seas. International Proceedings of Chemical, Biological and Environmental Engineering, 90, 152-158. https://doi.org/10.7763/IPCBEE. 2015. V90. 24

Walsh, W.A., \& Brodziak, J. (2014). Billfish CPUE standardization in the Hawaii longline fishery: Model selection and multimodel inference. Fisheries Research, 166, 151-162. https://doi.org/10.1016/j.fishres.2014.07.015

Wang, S.-P. (2018). CPUE standardization of striped marlin (Tetrapturus audax) caught by Taiwanese large scale longline fishery in the Indian Ocean. Paper Presented on 16th Working Party on Billfish, Cape Town, South Africa, 4-8 September 2018, IOTC-2018-WPB16-18, 31.

Wang, S.-P. (2019). CPUE standardization of blue marlin caught 
by Taiwanese large scale longline fishery in the Indian Ocean. Paper Presented at 17th Working Party on Billfish, La Reunion, France, 9-12 September 2019. IOTC2019-WPB17-18, $41 \mathrm{pp}$.

Yokoi, H., Semba, S., Satoh, K., \& Tsutomu, N. (2016). Standardization of catch rate for black marlin (Istiompax indica) exploited by the Japanese tuna longline fisheries in the Indian Ocean (1971-2015). Paper Presented on 14th Working Party on Billfish, Victoria, Seychelles, 6-10 September 2016, IOTC-2016-WPB14-19_Rev1, 17.
Yu, W., Masumoto, Y., Hood, R.R., D’Adamo, N., McPhaden, M.J., Adi, R., Tisiana, R., Kuswardani, D., Feng, M., \& Ivey, G. (2015). The Eastern Indian Ocean Upwelling Research Initiative Science Plan and Implementation Strategy. First Institution of Oceanography.

Zhou, S., Campbell, R.A., \& Hoyle, S.D. (2019). Catch per unit effort standardization using spatio-temporal models for Australia's eastern tuna and billfish fishery. ICES Journal of Marine Science, fszO34.

https://doi.org/10.1093/icesjms/fsz034 